\title{
Compositional modelling of element cycling in soil and plants - a case study from Northern Finland
}

\author{
SOLVEIG POSPIECH ${ }^{1}, \mathrm{~K}$. GERALD VAN DEN \\ BOOGAART $^{2}$, RAIMON TOLOSANA-DELGADO ${ }^{2}$, PERTTI \\ SARALA $^{3}$, JANNE KINNUNEN ${ }^{4}$ AND MAARIT \\ MIDDLETON $^{3}$ \\ ${ }^{1}$ Helmholtz-Zentrum Dresden-Rossendorf e.V. \\ ${ }^{2}$ Helmholtz Institute Freiberg, Helmholtz-Zentrum Dresden- \\ Rossendorf \\ ${ }^{3}$ Geological Survey of Finland GTK \\ ${ }^{4}$ Mawson Oy \\ Presenting Author: s.pospiech@hzdr.de
}

Modelling element enrichment into upper soil and uptake from soil to the plant organs in natural systems is challenged by the complexity due to mutual interaction of numerous processes and parameters. These parameters include the elemental composition of the sources like different soil horizons or underlying bedrock, varying availabilities of ions, redox conditions in the rhizosphere, and the characteristics of the plant species and their reaction to environmental changes like weather and climate. In this study, we present statistical models based on the principles of compositional data analysis (CoDa-principle) to decipher in a multi-variate and multi-parameter data set the major factors for element cycling between soil and plants.

The test site is located in a natural boreal forest area in Northern Finland and covers an area of ca. $4 \mathrm{~km}^{2}$. A stratified random sampling approach had been used to determine 90 sampling locations. For each location, soil samples of B-horizon and Ah-horizon and plant samples of Common Juniper, Norway Spruce and Scots Pine had been collected. The B-horizon samples had been analysed with XRF methods, Aqua regia and Ionic Leach. The Ah-horizon samples had been analysed by modified Aqua regia and Sodium pyrophosphate leach. Additionally, for each sampling location the soil conductivity, soil dielectric permittivity and $\mathrm{pH}$ had been measured. For the plants, the subsamples of twigs, needles and barks had been separately analysed. The elemental composition of all data sets is given as concentration values.

Because the concentrations are by definition constraint data and the uptake of one element often depends on concentration of other elements, the data analysis is performed on log-ratios scores of the elements instead of concentrations to avoid spurious effects in the data analysis. Three different conceptual models had been defined for the uptake: (1) specific, plant controlled, (2) regulated and (3) unspecific, source controlled. These uptake models can be represented by compositional (Aitchison-space) linear models. It is shown, how this approach can be used to model the influence of elemental composition of sources, the availability of elements in aqueous solutions and the influence of $\mathrm{pH}$ and conductivity on the uptake in the plant organs. 